\section{Russian science magazine dates from before the revolution}

Priroda, the Russian popular science journal, appeared in its 750th issue last month, with the original art nouveau cover of 1912, and containing reprints of significant articles published in the last 66 years. Any cover from the early years of the century must inevitably have an aura of the antique, but the first Priroda, with its antiquated spellings and obsolete letters comes as something of a shock-the very orthography is at once a living reminder that this is a journal from before the Revolution.

Priroda was founded in 1912, the same year in which Pravda, albeit illegally and abroad, first saw the light of day. Priroda was founded as a popular science journal, under the auspices of the "Man and Universe" Society, and its pre-Revolutionary editors included Vladimir A. Vagner (biologist and physiologist), Lev V. Pisarzhevskii (chemist), Lev A. Tarasevich (microbiologist) and Nikolai K. Kol'tsov (biochemist). From this era, the jubilee issue reprints Il'ya $\mathrm{I}$. Mechnikov's 1915 address to the Pasteur Institute, and a fascinating article by Maksim Gor'kii on "Science and democracy" which appeared in May 1917, during the heady political turmoil between the February and October Revolutions.

Revolution, however exciting, does not favour the publication of science, although Priroda managed to struggle through, albeit with occasional double issues until 1920. The following year, it was refounded as the organ of the "Commission for the Study of Natural Productive forces of the Academy of Sciences of the USSR" and the place of publication transferred from Moscow to Petrograd. In 1930 it came under the direct auspices of the Academy. During these years, the nature of the journal changed, becoming increasingly specialised, although some papers, such as Pavlov on "The activity of the higher nervous system" (1932), Vernadskii on the evolution of species and Artsimovich and Alikhan'yan on "the problems of the physics of the atomic nucleus" (1941) still seem aimed at the interested amateur rather than the specialist. An interesting reprint from this time is "The problem of the genesis of cultivated plants in our present state of knowledge", by Nikolai I. Vavilov, who was later to be discredited by the Lysenkoists and was only fully (posthumously) rehabilitated in 1971 .

In 1951, a special resolution of the Academy restored Priroda to its original purpose, the popularisation of science, and the specialist articles were

banished to more learned forums. At the same time, the editorial offices were moved back to Moscow. The format of Priroda, with prominent scientists, often Academicians, writing for the popular market survey articles on the achievements of Soviet and foreign science became essentially that we know today. With the passing of Stalinism, humour took a lighter touch - one recalls in particular the cartoon of the female biochemist earnestly knitting a double helix, while at the same time often subtly critical of official policy or negligence (the lab. assistant
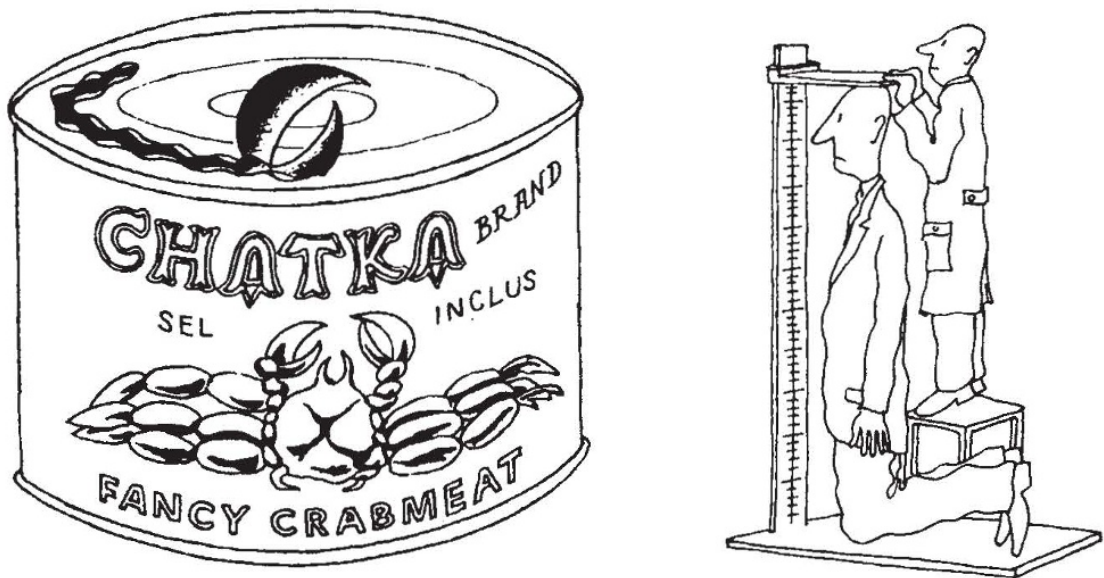

Priroda style humour: the saving mutation (left): science always finds a way out (right)

throwing tin-cans and cigarette ash into the fish-tank "to create a natural environment"). Humour is not lacking from the jubilee issue, taking the form of the regular round-up of literaturebut in this case looking forward to
December 1998 and Priroda 1000. (Anticles 'reviewed' include "The radiation of blue holes in the pink part of the spectrum", "The proposed international alphysical dictionary", a declaration from the Academy that they will not consider articles on telepathy "since the telepathic link has been conclusively proved", reports of traces of organic compounds in moon rock, and Dirac monopoles whose vibrations reproduce the "old-time lovesong" Ochi cherniya!)

Turning from fantasy to fact, and congratulating Priroda on its enduring standards and impressive survival and equally impressive circulation figure $(85,000)$, one must not fail to remark one minor

\title{
Czechs and Soviets meet in record space flights
}

Czechoslovakia has won the "little space race" for the third nation to put a citizen into orbit. The Czechs were odds-on favourites, although Poland and East Germany are confidently expected to 'place' later this year. The launch of 'Pilot Cosmonaut of the Czechoslovak Socialist Republic' Vladimor Remek, as one of the crew of Soyuz-28 is not, of course, unexpected; the Interkosmos programme envisaged the participation of Comecon cosmonauts, each with a Soviet partner, in Soyuz flights starting this year, and it has been rumoured for some weeks that these "international" flights would dock with the Salyut station. The only contention was which of the eight 'junior partners' in the alliance would be first.

Czechoslovakia has from the beginning been a major contributor to detail. The 1912 cover gives the price of a single issue as 50 kopeks. Two world wars, two revolutions and 66 years later the cost of a single issue remains-50 kopeks.

Vera Rich

Interkosmos, both in technical expertise and the provision of tracking facilities. Nevertheless, the Czech press played down this aspect, maintaining (Rude Pravo) that the joint flight was an example of Soviet selflessness and the principles of proletarian and specialist internationalism, and stressing (Zemedelske Noviny) that the Soviet Union bore about $95 \%$ of the cost of the Interkosmos programme-a claim that can neither be confirmed nor refuted, in view of Soviet reluctance to publish estimates for the space programme.

The new 'international' link-up was certainly the occasion for considerable euphoria-both at the control centre 'somewhere near Kalingrad' and in orbit. Indeed, the celebrations aloft seem to have exceeded expectations, since, according to the flight director 
A. Eliseev, the four cosmonauts "despite a great deal of persuasion from control" had not quietened down until late.

In spite of the excitement of this second linkage, the experimental programme of the mission is continuing to plan. The new crew are involved in an experiment with chlorella and have placed a capsule in the 'Splav' alloying chamber, which is designed to produce alloys of, for example, aluminiumtungsten and monlybdenum-tungsten, which would be impossible except in low or zero gravity conditions. (The particular 'Splav' experiment in which Remek is involved has been named 'Morava' in honour of Czechoslovakia).

However, according to Yakov Ziman of the Soviet Institute of Space Research, the space programme for 1976-80 (including the Comecon Interkosmos programme) is particularly concerned with the earth. Not surprisingly, the over-all plans for Salyut6 have included a considerable geophysical programme which has been going forward steadily throughout the mission. Whereas the Soyuz-22 photographs were "purely scientific", only one-tenth of the Salyut-6 survey is devoted to pure research; the rest are tailored to the requirements of various Ministries, government departments and design organisations.

Much of the data brought back by the crew which visited Salyut at the end of January was at once processed and transmitted to these 'clients', including various organisations involved in opening up the route of the BaikalAmur Mainline railway, and the constructors of the new hydroelectric installations in the highly-seismic vicinity of the Nurek dam.

Other photographic surveys include the monitoring of ocean currents (including oil slicks), and a special study of the glaciers and snow cover of the mountains of Soviet Central Asia. Space photographs are used to monitor glacier movements-a recent TASS announcement claims that over 30,000 "pulsating" glaciers have been discovered in the Pamirs using space photography.

Grechko is apparently a fairly talented antist in the 'space' medium of coloured pencils and felt-tipped pens. This gift is being used in the observation of ocean currents and the aurora borealis. In the case of the ocean observations, there seem to have been some initial difficulties in recording the currents-the colours observed went beyond the scale provided by the oceanologists. Special attention in all such visual observations is being paid to a phenomenan noted by the crew of Soyuz-25-under certain circumstances cloud cover can act as a "gigantic lens" so that waves, for example,

appear considerably magnified.

Other phenomena sketched by Grechko include Venus rises and sunrise over a clear horizon. Some of these sketches were brought back by Soyuz26 and are being studied at the Leningrad Optical Institute. The aurora borealis appearances sketched by Grechko coincided with observations of noctilucent clouds, although, according to Professor Aleksandr I. Lazareev of the Leningrad Optical Institute, it was difficult to establish any link between the two. These were the first space observations of noc-

\section{Voyager scientific platform jammed}

VOYAGER 1, the spacecraft launched last summer by the National Aeronautics and Space Administration as part of a joint project to Jupiter and Saturn, has developed an equipment fault which poses a major threat to the scientific success of the mission.

The problem has been caused by a malfunctioning of the scan platform (shaded on diagram) which contains most of the major scientific equipment to be used on the mission, including two television cameras, a cosmic ray detector, a photopolarimeter and ultraviolet and infrared spectrometers.

The platform is designed to rotate along two separate axes-an azimuth axis and an elevation axis - in such a way that the equipment can be pointed at any desired object either in the sky or on the surface of the two planets.

During calibration tests two weeks ago, the movement of the platform on its azimuth axis slowed down to such an extent that it was unable to complete a particular maneouvre in the onehour's computer time alloted, and thus failed to reach the required position.

Further commands issued from earth met with the same response. And al- tilucent clouds in the southern hemisphere, although they had been observed in the northern hemisphere from Salyut-4.

By combining Grechko's observations with data from meterorological rockets launched from the Antarctic Molodezhnaya station it has been deduced that moclilucent clouds have a multi-layer structure, occurring at local temperature minima. A threelayer structure is postulated, distributed at temperatures of -130 to $-150{ }^{\circ} \mathrm{C}$.

Vera Rich though it was initially suggested that the problem was due to an electronic failure in the spacecraft's computer system, it is now thought that the jamming of the platform is due to a mechanical cause.

Scientists at NASA's Jet Propulsion Laboratory in Pasadena, from which the Voyager mission is being directed, are making a hurried analysis of the spacecraft's pre-flight test data, to see if they can find any anomalies in performance which were previous overlooked.

Their intention is to produce a set of diagnostic commands which can be transmitted to the spacecraft. Voyager's reaction to these commands will, it is hoped, enable a fault to be analysed and corrected.

Dr Raymond L. Heacock, programme manager for the Voyager mission, said last week that even if it was impossible to rectify the fault, it would still be possible to get the equipment pointing in desired directions by maneouvring the whole spacecraft. Thus scientific data could still be transmitted back to earth.

However such a procedure would

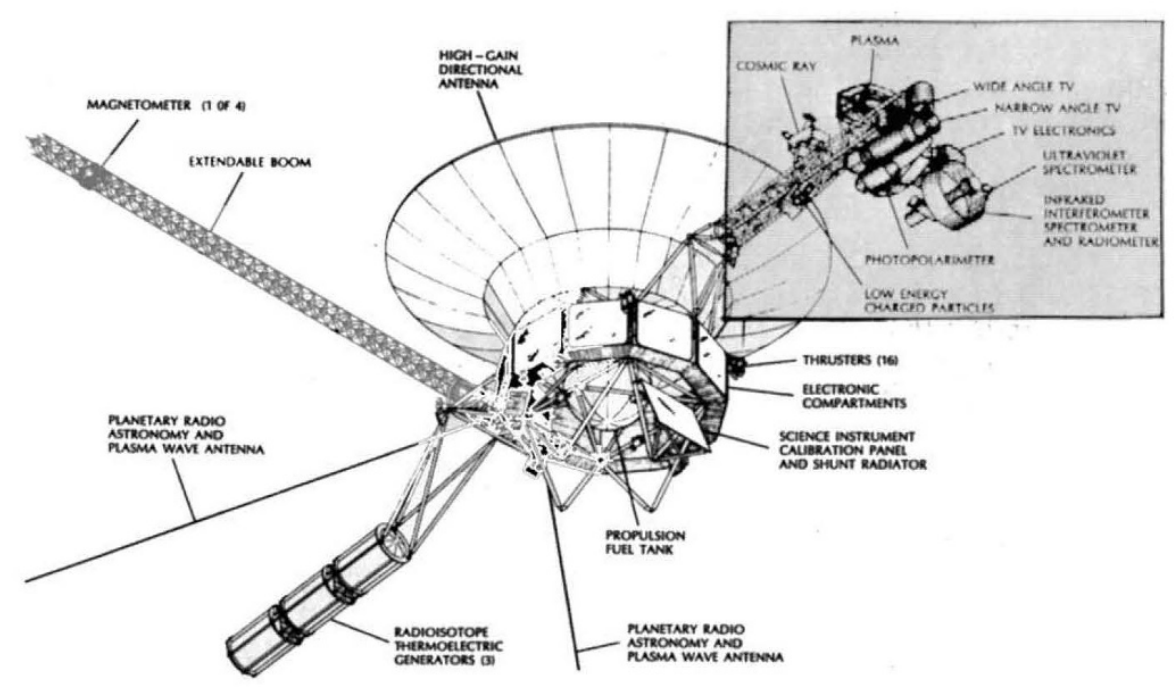

